\section{Assessment of post-operative pain in children: who knows best?}

\author{
Anjalee Brahmbhatt, Tope Adeloye, \\ Ari Ercole, Steven M. Bishop, \\ Helen L. Smith, Daniel W. Wheeler \\ University of Cambridge and Cambridge \\ University Hospitals NHS Foundation \\ Trust, UK
}

\section{Abstract}

Pain assessment in children can be extremely challenging. Most professional bodies recommend that parents or carers should be involved with their child's pain assessment; but the evidence that parents can accurately report pain on behalf of their children is mixed. Our objective was to examine whether there were differences in post-operative pain score ratings between the child, nurse and parent or carer after surgery. Cognitively intact children aged four upwards, undergoing all surgical procedures, whose parents were present in the post-anaesthetic recovery unit (PACU), were studied. Thirty-three children were included in the study. The numerical rating scale was used to rate the child's pain by the child, nurse and parent on arrival to the PACU and prior to discharge. We found strong correlations between children's, nurses' and parent's pain scores on admission and discharge from PACU. The intraclass correlation coefficient of pain scores reported by children, nurses and parents was 0.94 (95\% confidence intervals $0.91-0.96, \mathrm{P}<0.0001)$. In cognitively intact children, it is adequate to manage pain based upon the assessment of children's and nurses' pain scores alone. The numerical rating scale appeared to be suitable for younger children. Whilst there are benefits of parents being present in recovery, it is not essential for optimizing the assessment of pain.

\section{Introduction}

It is important to recognise and manage pain effectively as soon as possible, should a child be uncomfortable on waking after surgery. Inadequately treated pain will only add to the stress and anxiety of the child's experience of hospital. The three main principles of assessing pain in children are self-reporting, measuring the perceived experience of pain by the parent or carer, and measuring physiological arousal consequent to pain. ${ }^{1}$ Self-reporting is often considered the gold standard as it is the only direct measure of pain. However, there are various instances where it is difficult or impossible for children to state their own pain scores. In children who are cognitively impaired, critically ill, and those who are too young to speak, a proxy measure must be used.

Many national bodies strongly encourage parental input in children's pain assessment. In some instances, an assumption is often made that children are incapable of adequately quantifying their own pain.

In the United Kingdom (UK), the Royal College of Nursing (RCN) has recently updated its evidence-based recommendations on the assessment of acute pain in children. ${ }^{2}$ These include giving written information and advice on pain assessment and treatment to parents as part of their preparation for discharge after surgery, and teaching them to use pain assessment tools to help them manage their child's pain. The Association of Paediatric Anaesthetists in the UK also recommend that whilst children's self-report of their pain is the preferred approach, health care professionals and parents should receive information and training in pain assessment. ${ }^{1}$ In all cases, children's pain should be documented and appropriate action taken. In most hospitals, current practice dictates the documentation of children's and nurses' pain scores only.

The aim of this study was to investigate primarily whether pain rating scores differed between the patient, nurse and parent immediately after surgery. When a child emerges from anaesthesia in the post-anaesthetic recovery unit (PACU), parents are not always immediately present. Pain is a subjective experience, and it is possible that a child might not be able to report pain precisely in unfamiliar surroundings. We also investigated whether pain scores were being routinely documented in the PACU, and whether children's pain scores changed during their stay prior to discharge to the ward.

\section{Materials and Methods}

A prospective pilot study was performed in Spring 2009. Children over the age of four undergoing all operations and surgical procedures were included. Exclusion criteria included children whose parents were unable to attend the PACU, children unable to communicate or undertake elementary counting and those who were insufficiently rouseable at the time of data collection.

A pro forma was used to collect data in a uniform manner and included age and gender of patient, surgical procedure, intra-operative and post-operative analgesia administered and pain scores. Children, parents and nurses were not aware of each other's scores. The numeri-
Correspondence: Daniel W. Wheeler, University of Cambridge, Division of Anaesthesia, Box 93, Addenbrooke's Hospital, Hills Road, Cambridge, CB2 0QQ, UK.

Tel. +44.1223.217889 - Fax: +44.1223.217887.

E-mail: dww21@cam.ac.uk

Key words: pain measurement, nursing, postoperative diagnosis, child behavior, parents, psychology.

Acknowledgements: this study was funded by departmental funds of the Division of Anaesthesia, University of Cambridge and the Department of Anaesthetics, Addenbrooke's Hospital, Cambridge.

Contributions: $\mathrm{AB}, \mathrm{DWW}$, writing of the paper; $\mathrm{TA}$, data collection; AE, SB, statistical analysis; HS, supervising study.

Conflict of interest: Dr. Wheeler has received lecture fees and sponsorship of attendance at a conference from Pfizer. The University of Cambridge Division of Anaesthesia is the recipient of an unrestricted educational grant from Cephalon.

Funding: Dr. Wheeler's work is supported by the Association of Anaesthetists of Great Britain and Ireland, and the Medical Research Council of the United Kingdom.

Received for publication: 29 December 2011. Accepted for publication: 7 January 2012.

This work is licensed under a Creative Commons Attribution NonCommercial 3.0 License (CC BYNC 3.0).

(C) Copyright A. Brahmbhatt et al., 2012

Licensee PAGEPress srl, Italy

Pediatric Reports 2012; 4:e10

doi:10.4081/pr.2012.e10

cal rating scale (NRS) 0-10 was used as the pain assessment tool. ${ }^{1}$ Parents and children were provided with information about the numerical rating scale once the child entered the PACU. Nursing staff documented and acted upon pain scores in the usual manner until the child was ready for discharge to the ward.

We recorded the scores collected within 10 min of each child's arrival and 5 min before discharge from the PACU. We used statistical tests for non-parametric data to analyse our results. The Kruskal-Wallis test was used to test for differences in pain scores recorded by the children, nurses and parents. The Wilcoxon signed rank test was used to examine whether pain scores changed significantly between admission to PACU and discharge. (GraphPad Prism version 4.0b, GraphPad Software Inc., La Jolla, CA, USA), and oneway intraclass correlation coefficients (ICCs) to quantify the level of agreement between chil- 
dren, nurses and parents (R Project, Vienna, Austria $^{3}$ ). Statistical significance was considered to be a p value of less than 0.05 . Data are presented as mean (95\% confidence intervals, $\mathrm{CI})$ and the intraclass correlation coefficient (ICC) is reported with the value of the F statistic. Institutional approval was obtained for the conduct of the study.

\section{Results}

Thirty-three children aged between 4 and 16 years participated in the study, none were excluded. They underwent a variety of abdominal, urological, orthopaedic and otorhinolaryngological surgical procedures. Pain scores were documented for all patients. Pain scores of the child, nurse and parent immediately on admission to and discharge from the PACU are shown in Figure 1. Twenty-one out of 33 patients (64\% of cases) reported no pain immediately after their operation. The immediate post-operative mean pain score of the child, nurse and parent was 2.24 (95\% CI 1.053.44), 1.94 (95\% CI 0.84-3.04), and 2.55 (95\% CI 1.33-3.76) respectively. There was no statistical difference in pain scores between patient, nurse and parent on admission to recovery $(\mathrm{P}=0.66)$.

Children, nurses and parents all reported statistically significant improvements in children's pain scores between admission and discharge from PACU (Table 1). As analgesics were administered to the children in the PACU, the intensity of pain reported by each group fell significantly for all groups $(\mathrm{P}=0.003$, 0.006 and 0.001 for children, nurses and parents respectively). The mean pain score before discharge from PACU of the child, nurse and parent was 1.03 (95\% CI 0.37-1.69), 0.88 (95\% CI $0.31-1.45)$ and 1.06 (95\% CI $0.46-1.66)$

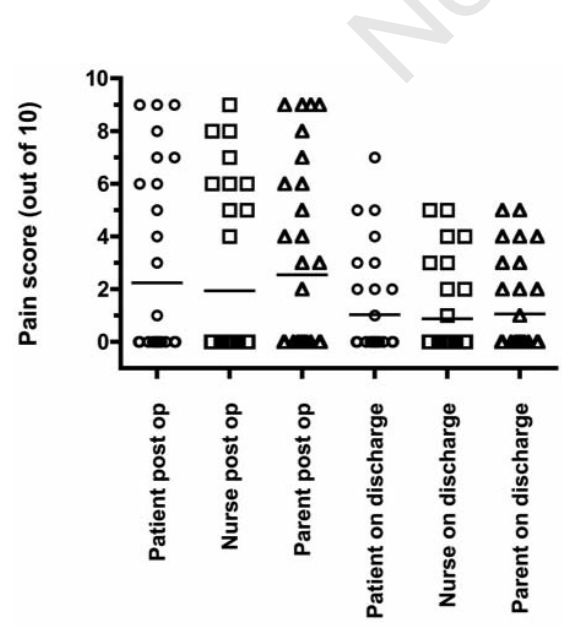

Figure 1. Scatter plot of pain scores given by children, nurses and parents recorded in the post-anaesthesia care unit (PACU). respectively. There was no statistical difference in pain scores between patient, nurse and parent on discharge from PACU $(\mathrm{P}=0.88)$.

There was strong agreement between children's, nurses' and parents' pain scores in the PACU (Figure 2). The ICC quantifies the strength of agreement: a value of 1.0 represents perfect agreement and zero represents complete disagreement. Overall, we found that the ICC was 0.94 (95\% CI 0.91-0.96, $\mathrm{P}<0.0001$, $\mathrm{F}=44.8$ ), showing very strong and highly statistically significant agreement between the raters. Agreement between raters was strong both on admission to the PACU and on discharge. The ICC of pain scores on admission was 0.91 (95\% CI 0.84-0.95, $\mathrm{P}<0.0001, \mathrm{~F}=29.7)$, and on discharge was 0.95 (95\% CI 0.90-0.97, $\mathrm{P}<0.0001, \mathrm{~F}=55.0$ ) (Table 2).

\section{Discussion}

We found strong correlations between the postoperative pain scores given by children, nurses and parents in the PACU. We also found that pain scores were being documented for all children and that pain was being adequately controlled and improved in the PACU prior to children being discharged to the ward. Furthermore, a numerical rating scale (NRS) appeared suitable for younger children.

Voepel-Lewis and colleagues have previously reported a reasonable correlation between pain scores given by cognitively impaired children and their parents when using a structured pain assessment tool, although some parents tended to overestimate their child's pain. 4 In an earlier study of children undergoing spinal surgery, the same investigators found that pain scores of cognitively impaired children were underestimated and lower doses of opioid analgesics were given compared to cognitively intact children. ${ }^{5}$ In cognitively intact children at risk of pain in a variety of settings, studies of how well others can quantify children's pain have yielded mixed results. Some studies have shown a good correlation in children on intensive care units ${ }^{6}$ and those receiving immunisations, ${ }^{7}$ whilst others have shown that parents tended to underestimate their child's pain after tonsillectomy, ${ }^{8}$ and triage nurses tend to underestimate pain in emergencies. $^{9}$

Although we found good agreements between pain scores given by children, nurses and parents immediately after surgery, it could be argued that our study was underpowered to detect clinically significant differences. Power analysis suggests that a study of this size would have had sufficient power to detect a difference in pain scores of 1.34 out of ten between the groups. This begs the question as to what is a clinically relevant difference between each group's ability to rate pain? We contend that a difference of one out of ten is not clinically important, and therefore our study was of sufficient size to detect a clinically important difference.

Parents and carers may benefit from being taught pain assessment tools if they are to be effective in assessing and managing their child's pain. ${ }^{10}$ This is especially useful in paediatric ambulatory surgery, where parents undertake a significant component of postoperative care at home. Parents should be provided with information that is easily understood. Tait and colleagues found that only a small amount of information regarding post-operative pain control was presented in written form yet many parents would have preferred both verbal and written information. ${ }^{10}$ Whilst it is desirable for parents to be present at all times during a child's admission to hospital, this may not always be possible. Our study has shown, at least after surgery, that PACU nurses are capable of accurately assessing and treating children with pain.

Deciding which pain assessment tool to use was challenging, as there are many currently in use. The topic has been a subject of great debate, with a number of studies devoted to pain assessment in children.11-14 The NRS was chosen for our study as parents may be familiar with it, it is straightforward, and easily taught. There have been suggestions that the NRS is not suitable for children younger than 8 years of age: de Tovar and colleagues published a study showing children's preference for the FACES scale after our data had been collected.15 However, some guidelines and researchers have suggested that the NRS can

Table 1. Children's, parents' and nurses' recorded pain scores on admission and discharge from the post-anaesthesia recovery unit.

\begin{tabular}{lccc} 
& Child's pain score & Nurse's pain score & Parent's pain score \\
$\begin{array}{l}\text { Mean score on admission } \\
\text { to PACU }(95 \% \mathrm{CI})\end{array}$ & $2.24(1.05-3.44)$ & $1.94(0.84-3.04)$ & $2.55(1.33-3.76)$ \\
$\begin{array}{l}\text { Mean score on discharge } \\
\text { from PACU }(95 \% \mathrm{CI})\end{array}$ & $1.03(0.37-1.69)$ & $0.88(0.31-1.45)$ & $1.06(0.46-1.66)$ \\
\hline Mean difference & $1.21(0.68-1.75)$ & $1.06(0.53-1.59)$ & $1.49(0.87-2.10)$
\end{tabular}

$(95 \% \mathrm{CI})$

Pvalue

0.003

0.006

0.001 
A)

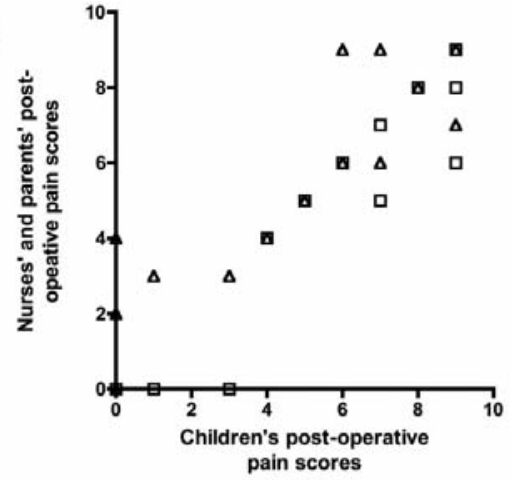

B)

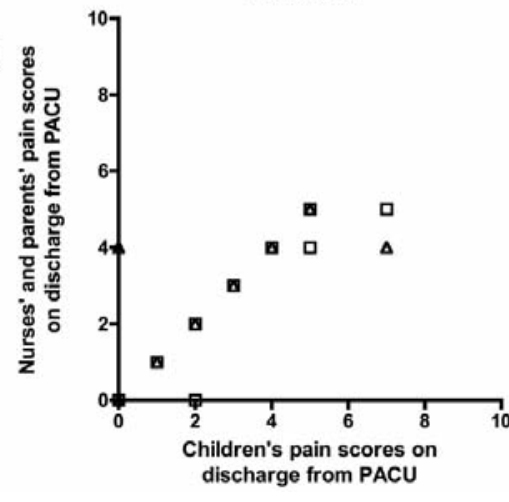

Figure 2. Graphs to show the relationship between pain scores given by children (on the $x$-axis), and nurses and parents (on the $y$-axis) recorded A) on admission to and B) on discharge from the post-anaesthesia care unit (PACU).

be used effectively in younger children,2,16 and, given the strength of the agreement between the scores that we found, use of the NRS should not automatically be ruled out in younger, cognitively intact children.

Our study was not large enough to examine whether the child's age might have influenced agreement between those rating the children's pain. It is also possible that the children with low initial pain scores may have overestimated the strength of the correlation we found. However, we contend that our paradigm could, on a larger scale, be used to study the influence of the rater on other pain assessment tools, such as FLACC (Face, Legs, Arms, Cry, Consolability), ${ }^{17}$ or self-report tools like FACES $15,18,19$ and the visual analogue scale 20 . or even to compare one with another. Other factors, such as introducing children and carers to pain rating scales before surgery, and calibrating them against known pains, could also be examined. Such an approach might be expected to reduce parental anxiety, and it would be worthwhile studying whether this influences parents' proxy pain scores for their children.

Whatever tools are used to assess pain, factors such as age, anxiety, language, ethnic background, the child's level of cognition, and level of parental education need to be taken

Table 2. The correlations between children's, parents' and nurses' recorded pain scores on admission and discharge from the post-anaesthesia recovery unit (PACU).

\begin{tabular}{lcccc} 
& $\begin{array}{c}\text { Nurses' } \\
\text { correlation with } \\
\text { child's score }\end{array}$ & Significance & $\begin{array}{c}\text { Parents' } \\
\text { correlation with } \\
\text { child's score }\end{array}$ & Significance \\
On admission to PACU & ICC $=0.94$ & $\mathrm{P}<0.0001$ & $\begin{array}{l}\text { ICC }=0.93 \\
(0.86-0.97)\end{array}$ & $\mathrm{P}<0.0001$ \\
& $(0.87-0.97)$ & & $\mathrm{I}$. & \\
On discharge from PACU & $\mathrm{ICC}=0.95$ & $\mathrm{P}<0.0001$ & $\mathrm{ICC}=0.92$ & $\mathrm{P}<0.0001$ \\
& $(0.90-0.98)$ & & $(0.83-0.96)$ & \\
\hline
\end{tabular}

into account by health care professionals before making an informed choice; 16 the UK Association of Paediatric Anaesthetists suggests that more than one might be necessary, stating that no individual measure can be recommended for pain assessment across all children or all contexts. ${ }^{1}$ There will always be a risk that pain will be underestimated, especially when a child is silent, perhaps as a result of the residual effects of anaesthesia. ${ }^{21}$ Thus a combination of self-report and at least one other measure may be a better approach than using a single tool.

In conclusion, we found strong correlations between children's, nurses' and parents' reported pain scores using a numerical rating scale. The finding that the numerical rating scale was a useful tool in a broader age range than expected was surprising, and warrants further study. In the mean time, we recommend that when cognitively intact children are recovering from surgical procedures an inclusive approach to pain management should be taken in the PACU, gauging the opinions of the patient, nurse and parent about the child's pain experience. Should the child not be able to express himself or herself, then nurses' and parents' assessments are highly likely to be accurate. Also, given the strong correlations we found, there is no need to delay treatment should the parents be absent. In children with cognitive impairment, parents should be integral to their child's pain assessment and be taught appropriate tools.

\section{References}

1. Howard R, Carter B, Curry J, et al. Pain assessment. Pediatric Anaesth 2008;18 Suppl1:14-8.

2. Royal College of Nursing, UK. Clinical practice guidelines: the recognition and assessment of acute pain in children. London: Royal College of Nursing 2009. Available from: http://www.rcn.org.uk/_data/assets/ pdf_file/0004/269185/003542.pdf

3. R Development Core Team (2010). R: A language and environment for statistical computing. $\mathrm{R}$ Foundation for Statistical
Computing, Vienna, Austria. ISBN 3900051-07-0. Available from: http//www.Rproject.org.

4. Voepel-Lewis T, Malviya S, Tait AR. Validity of parent ratings as proxy measures of pain in children with cognitive impairment. Pain Manag Nurs 2005;6:168-74.

5. Malviya S, Voepel-Lewis T, Tait AR, et al. Pain management in children with and without cognitive impairment following spine fusion surgery. Paediatr Anaesth 2001;11:453-8.

6. West N, Oakes L, Hinds PS, et al. Measuring pain in pediatric oncology ICU patients. $\mathrm{J}$ Pediatr Oncol Nurs 1994;11:64-8.

7. Stein PR. Indices of pain intensity: construct validity among preschoolers. Pediatr Nurs 1995;21:119-23.

8. Bellman MH, Paley CE. Pain control in children. Parents underestimate children's pain. BMJ 1993;307:1563.

9. Rajasagaram U, Taylor DM, Braitberg G, et al. Paediatric pain assessment: differences between triage nurse, child and parent. J Paediatr Child Health 2009;45:199-203.

10. Tait AR, Voepel-Lewis T, Snyder RM, Malviya S. Parents' understanding of information regarding their child's postoperative pain management. Clin J Pain 2008;24: 572-7.

11. Blount RL, Loiselle KA. Behavioural assessment of pediatric pain. Pain Res Manag 2009;14:47-52.

12. Franck LS, Bruce E. Putting pain assessment into practice: why is it so painful? Pain Res Manag 2009;14:13-20.

13. Prkachin KM. Assessing pain by facial expression: facial expression as nexus. Pain Res Manag 2009;14:53-8.

14. von Baeyer CL. Children's self-report of pain intensity: what we know, where we are headed. Pain Res Manag 2009;14:39-45.

15. de Tovar C, von Baeyer CL, Wood C, et al. Postoperative self-report of pain in children: interscale agreement, response to analgesic, and preference for a faces scale and a visual analogue scale. Pain Res Manag 2010;15:163-8.

16. Fanurik D, Koh JL, Harrison RD, et al. Pain assessment in children with cognitive impairment. An exploration of self-report 
skills. Clin Nurs Res 1998;7:103-19.

17. Malviya S, Voepel-Lewis T, Burke C, et al. The revised FLACC observational pain tool: improved reliability and validity for pain assessment in children with cognitive impairment. Paediatr Anaesth 2006;16: 258-65.

18. Wong DL, Baker CM. Pain in children: comparison of assessment scales. Pediatr Nurs
1988;14:9-17.

19. Bieri D, Reeve RA, Champion GD, et al. The faces pain scale for the self-assessment of the severity of pain experienced by children: development, initial validation, and preliminary investigation for ratio scale properties. Pain 1990;41:139-50.

20. Price DD, McGrath PA, Rafii A, Buckingham $B$. The validation of visual analogue scales as ratio scale measures for chronic and experimental pain. Pain 1983;17:45-56.

21. Bringuier S, Picot MC, Dadure C, et al. A prospective comparison of post-surgical behavioral pain scales in preschoolers highlighting the risk of false evaluations. Pain 2009;145:60-8. 